\title{
Preconceptional and postconception cerclage placement, dual case reports with review of literature
}

\begin{abstract}
Background: Cervical incompetence is defined as cervical insufficiency during the second trimester; characterized by painless cervical dilation, leading to expulsion of an immature fetus, with increased risk for future pregnancies to be complicated by preterm delivery. A cervical length less than $25 \mathrm{~mm}$ has been accepted as designating a short cervix and is an indication to implement measures to prevent fetal loss. Definitive treatment is placement of a cervical cerclage; to close, support, and/or strengthen the cervix by use of an encircling suture. There are two approaches for cervical cerclage placement - transvaginal, performed using the McDonald or Shirodkar technique, or transabdominal placed by laparoscope or laparotomy. The timing of placement can be either pre-conceptionally or post-conceptionally, dependent on patient presentation. We present a duel case report of cervical cerclage placement with a systematic review of cervical incompetency treated with pre-conceptional Shirodkar cerclage and postconceptional abdominal cerclage placement.
\end{abstract}

Case 1: 37-year-old Gravida 3, Para 0120, with history of spontaneous abortions (SAB) $x 3$ due to incompetent cervix resulting in one first trimester spontaneous abortions and two second trimester losses at 18 and 20 weeks, was treated with the preconceptional vaginal placement of Shirodkar cerclage. Subsequently, patient conceived spontaneously for the fourth time. Obstetrics ultrasound at 19 1/7 weeks showed cervical length of $4.01 \mathrm{~cm}$ with an intact Shirodkar cervical cerclage in place. Patient had uncomplicated prenatal care and underwent scheduled primary cesarean delivery at 37 weeks. Shirodkar cervical cerclage was remained in situ for future pregnancies.

Case 2: 30-year-old, Gravida 6, Para 1131, with history of recurrent pregnancy loss and cervical incompetency, underwent post-conceptional abdominal cerclage placement via laparotomy at 12 weeks and 2 days. Patient underwent repeat cesarean delivery at $355 / 7$ weeks due to early preterm labor and had uncomplicated postpartum recovery.

Conclusion: Recurrent pregnancy loss should take into consideration an incompetent cervix as a primary cause; and is treated via cerclage placement. Patients who failed to benefit from transvaginal cerclage may benefit from the simplified laparoscopic abdominal cerclage. With a known history of cervical incompetency, pre-conceptional cerclage should be considered to improve perinatal outcomes. Patients can benefit from indicated post-conception or rescue cerclage in the second trimester, if indicated.

Keywords: abdominal cerclage, cervical cerclage, cervical incompetence, cervical insufficiency; cervicoisthmic cerclage, preconceptional cerclage, postconception, preconception shirodkar cerclage, recurrent pregnancy loss, shirodkar cerclage, transvaginal cervical cerclage
Volume 9 Issue 5 - 2018

Shadi Rezai,' Neil D Patel, ${ }^{2}$ Danielle Kochen, ${ }^{2}$ Bhavin R Pandya,' Sarina C Lumapas,' Joel R Cohen,' Mon-Lai Cheung,' Basem Z Bernaba,' Omid Hakimian, ' Ray Mercado, ${ }^{3}$ Takeko Takeshige, ${ }^{4}$ Paul N Fuller,' Cassandra E Henderson ${ }^{5}$

'Department of Obstetrics and Gynecology, Southern California Kaiser Permanente, USA

${ }^{2}$ St. George's University, School of Medicine, Grenada

${ }^{3}$ Department of Obstetrics and Gynecology, Comprehensive Medical Care of the Bronx, USA

${ }^{4}$ Takeshige Medical, USA

${ }^{5}$ Maternal Fetal Medicine, Department of Obstetrics and Gynecology, Lincoln Medical and Mental Health Center, USA

Correspondence: Shadi Rezai MD, Department of Obstetrics and Gynecology, Southern California Kaiser Permanente, Kern County, I 200 Discovery Drive, Bakersfield, California, 93309, USA,Email rezsha@sgu.edu

Cassandra E Henderson MD, Maternal Fetal Medicine, Department of Obstetrics and Gynecology, Lincoln Medical and Mental Health Center, 234 East 149th Street, Bronx, New York, 1045I, USA, Email mdwstmd@aol.com

Received: July 25, 2018| Published: October 03, 2018

\section{Background}

Cervical incompetence is defined as cervical insufficiently during the second trimester. ${ }^{1}$ This process is characterized by painless cervical dilation with subsequent prolapse of membranes into the vagina resulting in the expulsion of an immature fetus; with an increased risk for future pregnancies. ${ }^{2}$ Individuals with exposure to diethylstilbestrol (DES), insufficient collagen and elastin, surgical trauma, mechanical dilation, and post-delivery trauma of the cervix are also at an increased risk for cervical incompetence. ${ }^{3}$

Cervical incompetence does not typically occur without a history of a second trimester loss. A screening ultrasound is used to assess cervical length and the presence of a funnel shaped opening (funneling) of the internal os, every two weeks beginning at 16 weeks gestation. ${ }^{1,4}$ Cervical length between $25-29 \mathrm{~mm}$ warrants a screening interval of once a week. Cervical length less than $25 \mathrm{~mm}$ denotes a short cervix, and measures are taken to decrease risk of fetal loss. ${ }^{1,5}$

The definitive treatment for cervical incompetence is placement of a cervical cerclage; the cervix is closed and/or tightened with an encircling suture. Patients can benefit from postconceptional or rescue cerclage in the second trimester, if indicated (Table 1).

With a known history of cervical incompetency in presence of transvaginal postconception cervical cerclage, for future pregnancy, one should may consider placement of pre-conceptional cerclage for improved perinatal outcomes (Table 1).

Contraindications for cerclage placement include bleeding, contractions, or ruptured membranes. ${ }^{2}$ Cervical cerclage placement will not improve perinatal outcomes or decrease the risk of premature birth for those pregnancies complicated by fetal anomalies incompatible with life, intrauterine infection, active bleeding or fetal demise in 
utero. ${ }^{6}$ There are two approaches for cervical cerclage placement (Table 2) - transvaginal, which can be done using the McDonald or Shirodkar technique, or transabdominal placed laparoscopically or laparotomy. The timing of placement can occur either pre- or postconception, depending on the patient's presentation. ACOG currently recommends management based on patient history and physical findings. History-based (pre-conceptional) cerclage placement is advocated in patients with previous history of insufficient cervix - unexplained second trimester delivery in the absence of labor or abruptio placentae. ${ }^{1}$ Physical exam (post-conceptionally) based management advocates for placement in the second trimester, $>24$ weeks, if cervical length $<25 \mathrm{~mm} .{ }^{1}$ ACOG initially recommends the transvaginal approach, if failed, supports use of transabdominal placement. $^{1}$

Table I Summary of Candidates for Preconceptional and Postconceptional Cerclage

\begin{tabular}{ll}
\hline Preconceptional Cerclage $^{2}$ & Postconceptional Cerclage $^{2}$ \\
\hline $\begin{array}{l}\text { Cervical insufficiency based on } \\
\text { multiple prior second trimester }\end{array}$ & $\begin{array}{l}\text { Advanced cervical dilation in } \\
\text { absence of uterine contractions }\end{array}$ \\
$\begin{array}{l}\text { losses } \\
\text { Abdominal cerclage indications: }\end{array}$ & $\begin{array}{l}\text { Short cervical length with or } \\
\text { waithout funneling between } 24\end{array}$ \\
$\begin{array}{l}\text { History of trachelectomy } \\
\text { Recurrent pregnancy loss or }\end{array}$ & and 34 weeks \\
spontaneous preterm delivery & \\
despite vaginal cerclage & \\
\hline
\end{tabular}

Table 2 Indication for Vaginal and Abdominal Cerclage

$\begin{array}{ll}\begin{array}{l}\text { Transvaginal Cerclage } \\ \text { ((Shirodkar / McDonald }\end{array} & \begin{array}{l}\text { Abdominal Cerclage (Laparotomy, } \\ \text { Laparoscopy, or Robotic) }\end{array} \\ \text { Cervical ) } & \end{array}$

History of one or more secondtrimester pregnancy losses with painless cervical dilation

Prior successful indicated cerclage

Second trimester painless cervical dilation

Singleton pregnancy $<24$ wks GA with cervical length $<25 \mathrm{~mm}$.

Previously failed transvaginal cerclage 16

Extremely short $(<15 \mathrm{~mm})$ cervix 16

Congenitally deformed cervix 16

History of trachelectomy

Deeply lacerated or scarred cervix 16

Recurrent pregnancy loss with failed vaginal cerclage

Spontaneous preterm birth with intact vaginal cerclage 14

We present a duel case report and systematic review for cervical incompetency in a patient treated with pre-conceptional Shirodkar cervical cerclage and another patient treated with post-conceptional abdominal cerclage placement.

\section{Presentation of the case I}

37-year-old Gravida 3, Para 0120, with a history of spontaneous abortions (SAB) $x 3$ due to incompetent cervix, resulting in one first trimester spontaneous abortion, and two second trimester losses at 18 and 20 weeks, was treated with the preconceptional vaginal placement of a Shirodkar cerclage. Placement was preceded by the use of a weighted speculum insertion and exposure of the anterior lip of the cervix followed by dissection of the posterior vaginal cervical mucosa. Dissection was carried up to expose the internal os. Parallel sutures were placed in the lower uterine segment and brought down tight with a square knot and tied posteriorly. Finally, additional sutures were placed on either side of the knot for complete closure and reduction.

Subsequently, patient conceived spontaneously for the fourth time, and was placed on daily administration of vaginal progesterone suppository. Obstetrics ultrasound at 19 1/7 weeks showed cervical length of $4.01 \mathrm{~cm}$ with an intact Shirodkar cervical cerclage in place (Figure 1). Patient had uncomplicated prenatal care and underwent scheduled primary cesarean delivery at 37 weeks. Shirodkar cervical cerclage was remained in situ for future pregnancies.

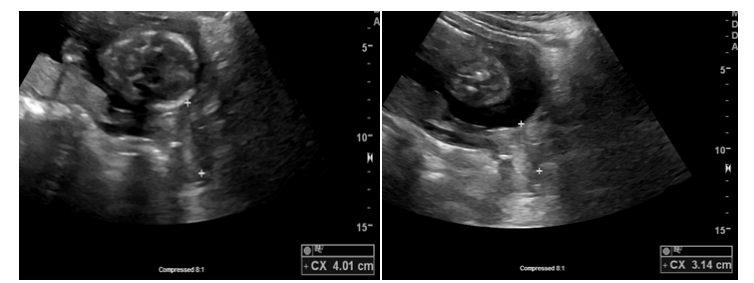

Figure I Patient Case I, Obstetrics ultrasound at I9 I/7 weeks showing cervical a length of $4.01 \mathrm{~cm}$ and $3.14 \mathrm{~cm}$ with an intact pre-conceptional vaginal Shirodkar cervical cerclage.

\section{Presentation of the case 2}

30-year-old, Gravida 6, Para 1131, with a history of recurrent pregnancy loss and cervical incompetency, underwent postconceptional abdominal cerclage placement via laparotomy at 12 weeks and 2 days. After confirming fetal viability, the patient was taken to the operating room; where the abdominal cavity was accessed through her old cesarean section scar down to the level of the internal os. The internal os was palpated, the uterine vessels were identified, and $5 \mathrm{~mm}$ Mersilene was introduced by placing a suture, first on the right side, parallel and immediately adjacent to the lower uterine segment internal os; similarly performed on the left side. A square knot was then placed with the Mersilene. It was sutured in place with 0 Ethibond going behind the Mersilene. The Mersilene had been cinched down to a level where it would admit a Pean clamp anteriorly for future expansion and growth. Postoperative transabdominal ultrasound confirmed detectable fetal heartbeat. Obstetric ultrasound at $213 / 7$ weeks showed cervical length of $4.20 \mathrm{~cm}$ with an intact cervical cerclage in place (Figure 2). Patient underwent repeat cesarean delivery at $355 / 7$ weeks due to early preterm labor and had uncomplicated postpartum recovery.

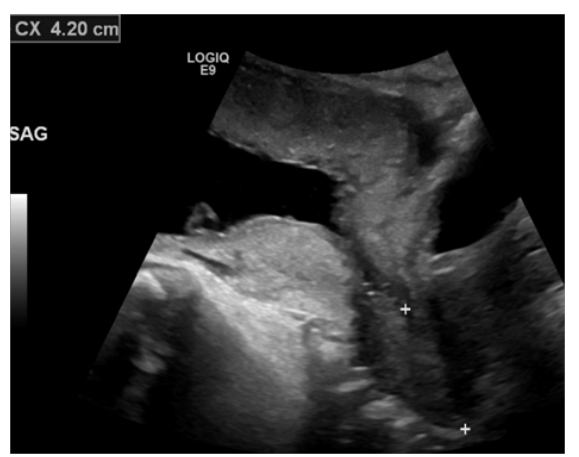

Figure 2 Patient Number 2, Obstetrics ultrasound at 21 3/7 weeks showing cervical length of $4.20 \mathrm{~cm}$ with an intact post-conceptional abdominal cervical. 


\section{Discussions}

Cervical cerclage placement can be done vaginally, abdominally via laparoscopy, laparotomy or robotic. The vaginal cerclage can be done by two methods, using either the McDonald or Shirodkar technique. The McDonald technique is a simpler procedure where a permanent suture, typically 2-O monofilament, encircles the body of the cervix near the level of the internal os. The suture is then tightened to decrease the diameter of the cervical canal between $5-10 \mathrm{~mm}$ and then secured in place. ${ }^{2}$ The Shirodkar technique involves a transverse incision over the anterior cervix so the bladder can be pushed cephalad. A second incision of the posterior vaginal epithelium is made at the junction of the posterior vaginal mucosa and cervical portio. 5-mm Mersilene tape is passed anterior to posterior on one side of the cervix and then posterior to anterior on the opposite side of the cervix. In addition to the Mersilene tape, 2-O permanent sutures may be places for stronger tie. The tape is tied and suture is used to close the overlying mucosa. ${ }^{2}$ In support, we advocate the Shirodkar procedure because the cerclage can be placed closer to the cervical uterine junction allowing for a more proximal stronger support of the cervix. ${ }^{7}$ However, investigators have shown that there is no significant difference in the prevention of preterm birth between the two transvaginal techniques. ${ }^{8}$

The transabdominal cerclage is placed at the uterine isthmus and has the benefit of being able to be used for future pregnancies. Placement begins through dissection of the vesicouterine space to observe the uterus. A non-absorbable suture is placed to maintain the closure of the cervix. The transabdominal approach can be done through laparotomy or laparoscopy. Respecting the provisions of invasive procedures, patients who failed to benefit from vaginal placement can benefit from the simplified laparoscopic approach. ${ }^{9}$ With the inherent advantages of laparoscopy, cerclage placement via laparoscopy is preferable, particularly in non-pregnant women - the rates of thirdtrimester delivery and live birth after laparoscopic cerclage placement are high and comparable to those via laparotomy. ${ }^{10,11}$ The Abdominal approach is typically reserved for individuals that have a previously failed transvaginal cerclage or have extremely short, congenitally deformed, deeply lacerated or deeply scarred cervix, and is typically placed at $<13$ weeks due to the size of the uterus and its ease of manipulation. ${ }^{12-15}$ It has been shown that patients with a traumatized cervix that precludes a transvaginal cerclage have successful outcomes with a transabdominal cervicoisthmic cerclage in the absence of procedure related complications. ${ }^{16}$

Cerclage placement can be evaluated in patients who have recurrent pregnancy loss, prompting preconception placement of a cerclage as intervention for future pregnancies. One case series reports that preconception transabdominal cervicoisthmic cerclage is a safe alternative with no risk to the fetus. ${ }^{17}$ It can be said that the transvaginal approach is easier when compared to the abdominal placement due to associated surgical risks. ${ }^{18}$ However, an additional advantage of the abdominal cerclage is that there is no effect on fertility rates or perinatal outcomes. ${ }^{19,20}$ One drawback of the abdominal cerclage is the potential migration of the suture or tape into the endocervical canal, leading to aggravation of the cervical insufficiency. Throughout the antenatal course this potential complication should be evaluated with replacement of the cerclage if indicated. ${ }^{21}$ In relation to abdominal cerclage placement before or during pregnancy, preconception placement is superior for the prevention of mid-trimester loss and decreases surgical and pregnancy related morbidity. ${ }^{22}$ Placement of a permanent cerclage impedes the natural delivery process; requiring cesarean deliveries. In addition, reports identify related intra-pregnancy complications such as bleeding, pyrexia and vaginal discharge. ${ }^{23}$

Even though cervical incompetency can be determined during the pre- and post- conceptional periods, emergent cervical insufficiency may present; most commonly, in the second trimester threatening early delivery and possible fetal loss. Studies suggest under ideal circumstances; emergency cerclage can significantly prolong pregnancy and increase the chance for viable outcomes. ${ }^{24}$ The major concerns pertaining to emergency cerclage stem from increased risk of chorioamnionitis and associated risk of fetal inflammatory brain injury; and the possibility of severe prematurity. ${ }^{24}$ However, the placement of an emergency rescue cerclage has shown to be a safe therapeutic option with a low rate of maternal morbidity, with a high rate of neonatal survival..$^{24,25}$ Other limitations towards placement can be due to degree of dilation, cervical length, rupture of membranes, or any sign of infection. ${ }^{26}$

An additional application of post-conceptional cerclage can be unconventionally advocated for during multiple gestation pregnancy. Although ACOG does not support the use of post-conceptional cerclage placement in multiple gestation pregnancies; new reports are being published supporting its use. Roman et al. ${ }^{15}$; Kliethermes et al. ${ }^{13}$ (Table 3) have demonstrated that post-conceptional abdominal cerclage intervention improves perinatal outcomes compared to conventional expectant management. Roman et al. ${ }^{15}$ recommends placement in multi-gestation women with dilated cervix greater or equal to $1 \mathrm{~cm}$, before 24 weeks. This supports longer latency periods long with decreased incidence of spontaneous preterm birth. As presented above, a laparoscopic abdominal approach may be used, ideally before 13 weeks gestation. ${ }^{13}$

Table 3 Advantage and Disadvantage of Cerclage Placement for Twins

\begin{tabular}{|c|c|}
\hline Advantages $^{2}$ & Disadvantage \\
\hline $\begin{array}{l}\text { Dilated cervix } \geq 1 \mathrm{~cm} \text { before } \\
24 \text { weeks associated with } \\
\text { longer latency period }\end{array}$ & Not ACOG Recommended ${ }^{2}$ \\
\hline $\begin{array}{l}\text { Decreased incidence of } \\
\text { spontaneous preterm birth }\end{array}$ & Increase risk of preterm birth ${ }^{2}$ \\
\hline $\begin{array}{l}\text { Improved perinatal outcomes } \\
\text { compared to expectant } \\
\text { management }\end{array}$ & $\begin{array}{l}\text { Not effective in prolonging gestation or } \\
\text { improving fetal outcomes } 10\end{array}$ \\
\hline
\end{tabular}

\section{Conclusion}

Recurrent pregnancy loss should take into consideration an incompetent cervix as a primary cause. The preferred mainstream treatment is cerclage placement, initially with the transvaginal approach. Patients who failed to benefit from vaginal cervical cerclage may benefit from the simplified laparoscopic abdominal cervical cerclage. ${ }^{9}$ With a known history of cervical incompetency, preconceptional cerclage should be considered for improved perinatal outcomes. Patients can benefit from postconceptional or rescue cerclage in the second trimester, if indicated.

\section{Acknowledgments}

None.

\section{Conflicts of interest}

Authors did not report any potential conflicts of interests. 


\section{References}

1. American College of Obstetricians and Gynecologists. ACOG practice bulletin NO. 142: Cerclage for the management of cervical insufficiency. 2014;123(2 pt 1):372-379.

2. Cunningham F, Leveno KJ, Bloom SL, et al. Williams Obstetrics, 25th ed. New York: McGraw-Hill; 2018.

3. Pawłowicz P, Ordon W, Malinowski A. Laparoscopic abdominal cervical cerclage before conception--case report. Ginekol Pol. 2009;80(12):949-952.

4. Zilianti M, Azuaga A, Calderon F, et al. Monitoring the effacement of the uterine cervix by transperineal sonography: A new perspective. $J$ Ultrasound Med. 1995;14(10):719-724.

5. Berghella V, Keeler SM, To MS, et al. Effectiveness of cerclage according to severity of cervical length shortening: A meta-analysis. Ultrasound Obstet Gynecol. 2010;35(4):468-473.

6. Hargar JH. Cerclage and cervical insufficiency: An evidence-based analysis. J Obstet Gynecol. 2002;100(6):1313-1327.

7. Ventolini G, Genrich TJ, Roth J, et al. Pregnancy outcome after placement of 'rescue' Shirodkar cerclage. $J$ of Perinatology. 2009;29(4):276-279.

8. Ventolini G, Genrich TJ, Roth J, et al. Pregnancy outcome after placement of 'rescue' Shirodkar cerclage. $J$ of Perinatology. 2009;29(4):276-279.

9. Huang X, Ma N, Li TC, et al. Simplified laparoscopic cervical cerclage after failure of vaginal suture: technique and results of a consecutive series of 100 cases. Eur J Obstet Gynecol Reprod Biol. 2016;201:146-150.

10. Burger NB, Einarsson JI, Brölman HA, et al. Preconceptional laparoscopic abdominal cerclage: A multicenter cohort study. Am J Obstet Gynecol. 2012;207(4):273.e1-12.

11. Tulandi T, Alghanaim N, Hakeem G, et al. Pre and post-conceptional abdominal cerclage by laparoscopy or laparotomy. J Minim Invasive Gynecol. 2014;21(6):987-993.

12. Debbs RH, DeLa Vega GA, Pearson S, et al. Transabdominal cerclage after comprehensive evaluation of women with previous unsuccessful transvaginal cerclage. Am J Obstet Gynecol. 2017;197(3):3017.e1-4.

13. Kliethermes CJ, Fox KA, Blazek KK, et al. Laparoscopic Twin Cerclage at 11 Weeks. J Society Laparoendoscopic Surgeons. 2018
14. Novy MJ. Transabdominal cervicoisthmic cerclage: A reappraisal 25 years after its induction. AM J Obstet Gynecol. 1991;164( pt 1):1635-1641.

15. Roman A, Rochelson B, Martinelli P, et al. Cerclage in twin pregnancy with dilated cervix between 16 to 24 weeks of gestation: retrospective cohort study. Am J Obstet Gynecol. 2016;215(1):98.e1-e11.

16. Lotgering FK, Gaugler-Sendin IP, Lotgering SF, et al. Outcome after transabdominal cervicoisthmic cerclage. Obstet Gynecol. 2006;107(4):779-784.

17. Groom KM, Jones BA, Edmonds DK, et al. Preconception transabdominal cervicoisthmic cerclage. Am J Obstet Gynecol. 2004;191(1):230-234.

18. Zaveri V, Aghajafari F, Amankwah K, et al. Abdominal versus vaginal cerclage after a failed transvaginal cerclage: a systematic review. Am J Obstet Gynecol. 2002;187(4):868-872.

19. Rust OA, Atlas RO, Meyn J, et al. Does cerclage location influence perinatal outcomes? Am J Obstet Gynecol. 200;189(6):1688-1691.

20. Vousden NJ, Carter J, Seed PT, et al. What is the impact of preconception abdominal cerclage on fertility: evidence from a randomized controlled trial. Acta Obstet Gynecol Scand. 2017;96(5):543-546.

21. Park MI, Hoh JK. Translocation of a cerclage band into the endocervical canal after preconception transabdominal cervico-isthmic cerclage. $J$ Obstet Gynaecol Res. 2010;36(1):209-212.

22. Dawood F, Farguharson RG. Transabdominal cerclage: preconceptual versus first trimester insertion. Eur J Obstet Gynecol Reprod Biol. 2016;199:27-31.

23. Alfirevic Z, Stampalija T, Roberts D, et al. Cervical stitch (cerclage) for preventing preterm birth in singleton pregnancy. Cochrane Database Syst Rev. 2012;18(4): CD008991.

24. Cockwell HA, Smith GN. Cervical incompetence and the role of emergency cerclage. J Obstet Gyneco Can. 2005;27(2):123-129.

25. DeStefano KA, Lin JT, Al-Kouatly H, et al. Rescue cerclage: we can make a difference. Obstet Gynecol. 2006;107(4):64S.

26. Dor J, Shalev J, Mashiach S, et al. Elective Cervical Suture of Twin Pregnancies Diagnosed Ultrasonically in the First Trimester Following Induced Ovulation. Gynecol Obstet Invest. 1982;13(1):55-60. 